\title{
Structure of a Novel Sialooligosaccharide from the Urine of a Patient with Mucolipidosis
}

\author{
Masai Koseki and Koichi Tsurumi \\ Department of Biochemistry, Fukushima Medical College, \\ Fukushima 960
}

\begin{abstract}
Koseki, M, and Tsurumi, K. Structure of a Novel Sialooligosaccharide from the Urine of a Patient with Mucolipidosis. Tohoku J. exp. Med., 1978, 124 (4), 361-366 _ A mannose-containing sialooligosaccharide has been isolated from the urine of a patient with a newly recognized mucolipidosis which showed a low liver $\beta$-galactosidase activity and hyperglycopeptiduria. The chemical structure has been determined by glycosidase digestion, Smith degradation and permethylation studies. The following structure has been given for the oligosaccharide: NANA $\alpha 2-6 \mathrm{Gal} \beta 1-4 \mathrm{GlcNAc} \beta 1-2 \mathrm{Man} \beta 1-3 \mathrm{Man} \beta 1-4 \mathrm{GlcNAc}$. This compound appears to be derived from an incomplete catabolism of glycoproteins with aspartylglucosylamine type side chains. —— sialooligosaccharide; mucolipidosis; lysosomal storage disease; sialoglucide
\end{abstract}

Although it has been widely known that mucolipidosis is one of the lysosomal storage diseases (Spranger and Wiedemann 1970), the biochemical defect of mucolipidosis has not yet been fully characterized except for mucolipidosis I (lipomucopolysaccharidosis) and mucolipidosis II (I-cell disease) (Hickman and Neufeld 1972; Neufeld et al. 1976).

In the previous study (Koseki et al. 1978) it was demonstrated that an abnormally large amount of mannose-containing sialoglucide was excreted in the urine of a patient with a newly recognized mucolipidosis reported by Orii et al. (1972). This patient showed a low $\beta$-galactosidase activity and hyperglycopeptiduria according to Orii et al. (1972).

In the present paper the authors report the isolation and characterization of a novel mannose-containing sialooligosaccharide excreted in an abnormal amount in the urine of this patient.

\section{Materials and Methods}

Sialoglucide fraction of the urine was isolated from the pooled urine sample $(5,000 \mathrm{ml})$ from the patient with a new type of mucolipidosis by the following procedure. A 5,000 $\mathrm{ml}$ urine was applied to an activated charcoal column $(5 \mathrm{~cm} \times 60 \mathrm{~cm})$, and the column was washed thoroughly with distilled water. The adsorbed materials were eluted with the mixture of ethanol, pyridine and water $(2: 1: 2$, by volume). The eluate, after the removal of organic solvent, was applied to a Dowex 50 (hydrogen form, 200-400 mesh) column (2.5 $\mathrm{cm} \times 30 \mathrm{~cm}$ ) mounted upon a Dowex $1 \times 2$ (acetate form, 200-400 mesh) column $(2.5 \mathrm{~cm} \times$ $40 \mathrm{~cm}$ ). After washing the columns with distilled water, sialoglucides which had been

Received for publication, August 23, 1977. 
retained on the Dowex $1 \times 2$ column were eluted with $1.0 \mathrm{M}$ pyridinium acetate, $\mathrm{pH}$ 5.3. The eluate was concentrated to a small volume, then applied to a Sephadex G-25 column $(2.5 \mathrm{~cm} \times 90 \mathrm{~cm})$ and fractionated with $0.1 \mathrm{M}$ pyridinium acetate, $\mathrm{pH} 5.3$. Fractions of $10 \mathrm{ml}$ were collected and the elution profile was monitored by the orcinol method. Three sialic acid-containing fractions were obtained (SG-1, $\mathrm{SG}-\mathbf{1}^{\prime}$ and $\left.\mathrm{SG}-2\right)$. The fraction $\mathrm{SG}-\mathbf{1}^{\prime}$ was rechromatographed on a Sephadex G-25 column and purified further by linear gradient elution chromatography ( 0 to $0.1 \mathrm{M}$ pyridinium acetate) followed by preparative paper chromatography on Toyo Roshi No. 131 filter paper. The filter paper was developed in ethylacetate-pyridine-acetic acid-water $(5: 5: 1: 3$, by volume) for three days in descending way.

Chemical composition of the purified sialooligosaccharide was examined by the conventional colorimetric analyses and by gas-liquid chromatography. The samples for the assay were hydrolyzed in $2.5 \mathrm{~N}$ trifluoroacetic acid at $100^{\circ} \mathrm{C}$ for $6 \mathrm{hr}$. Gas chromatographic analysis was performed under the condition described by Tamura et al. (1968). Sequential degradation study was carried out by the use of glycosidases according to the method of Fukuda and Egami (1971). The glycosidases used were Arthrobacter ureafeciens sialidase (Uchida et al. 1977), Charonia lampas $\beta$-galactosidase, Turbo cornutus $\beta$-Nacetylhexosaminidase and $\alpha$-mannosidase. The Smith degradation was applied to the oligosaccharide according to the method described by Kuhn and Gauhe (1965). The intact sialooligosaccharide and its asialo-derivative and dimannosyl- $\mathrm{N}$-acetylglucosamine, which had been obtained by sequential digestion of the asialooligosaccharide with $\beta$-galactosidase and $\beta$-N-acetylhexosaminidase, were subjected to permethylation analysis according to the method of Hakomori as described by Sandford and Conrad (1966). The analysis of partially methylated alditol acetates was performed by gas-liquid chromatography according to Björndal et al. (1967).

\section{Results}

The elution profile of the urinary sialoglucide from the Sephadex G-25 column showed three overlapping peaks (Fig. 1). The intermediate fraction (SG-1') was purified further by repeated gel filtration on a Sephadex G-25 column, ion exchange chromatography and preparative paper chromatography. The yield was $254 \mathrm{mg}$ from $5,000 \mathrm{ml}$ of the urine. Fig. 2 shows the chromatogram of the sialooligosaccharide fraction on a Dowex $1 \times 2$ column.

Chemical analysis of the purified sialooligosaccharide revealed that it was a hexasaccharide consisted of $\mathrm{N}$-acetylneuraminic acid (1.0), galactose (1.0), mannose (2.0) and $\mathrm{N}$-acetylglucosamine (2.0). Analytical evidence is as follows: Borohydride treatment of the purified material resulted in the production of one mole of $\mathrm{N}$-acetylglucosaminitol, showing that the reducing end of this oligosaccharide is occupied by $\mathrm{N}$-acetylglucosamine residue. Table 1 shows the analytical data.

An attempt to digest the intact oligosaccharide with $\beta$-galactosidase, $\beta$ - $\mathrm{N}$-acetylhexosaminidase and $\alpha$-mannosidase was unsuccessful. But the asialo-derivative of the sialooligosaccharide released one mole each of galactose, $\mathrm{N}$-acetylglucosamine and mannose on sequential incubation with above mentioned glycosidases. The results of the enzymatic experiment are shown in Table 2.

The results of the permethylation study of the intact and the asialooligosaccharide and dimannosyl-N-acetylglucosamine are shown in Table 3 and Fig. 3. The data of permethylation analysis, together with the results obtained by the digestion study and the chemical analysis, show that the asialo-derivative of the 


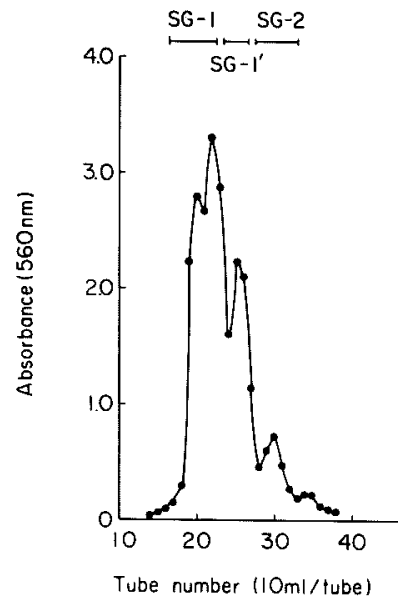

Fig. 1

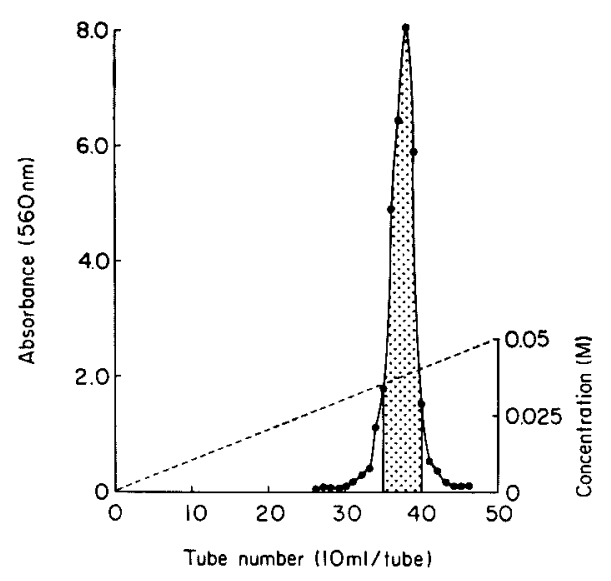

Fig. 2

Fig. 1. Elution pattern of the crude urinary sialoglucide on a Sephadex G-25 column.

Fig. 2. Elution profile of the crude sialooligosaccharide fraction (SG-1') in Dowex $1 \times 2$ ion exchange chromatography in a linear gradient system from 0 (mixing chamber, $400 \mathrm{ml}$ ) to $0.1 \mathrm{M}$ pyridinium acetate, pH. 5.3 (reservoir, $400 \mathrm{ml}$ ). Solid line, absorbance at $560 \mathrm{~nm}$; dotted line, concentration of pyridinium acetate buffer.

TABLE 1. Carbohydrate composition of the purified urinary sialooligosaccharide (mmoles/100 g)

\begin{tabular}{ccccccc}
\hline Sample & $\begin{array}{c}\text { Total } \\
\text { hexose }\end{array}$ & Galactose & Mannose & Glucosamine & Sialic acid & Morgan-Elson \\
\hline $\begin{array}{l}\text { Urinary sialooligo- } \\
\text { saccharide }\end{array}$ & 254.4 & 86.1 & 168.3 & 175.4 & 84.5 & - \\
$\begin{array}{c}\text { Borohydride-reduced } \\
\text { urinary sialooligo- } \\
\text { saccharide }\end{array}$ & 242.4 & 81.6 & 159.7 & 72.4 & 84.4 & n.d. $\dagger$ \\
$\begin{array}{l}\text { Gal } \text { Man }_{2} \text { GlcNAc } \\
\text { NANA* }\end{array}$ & 249.8 & 83.3 & 166.6 & 166.5 & 83.3 & - \\
\hline
\end{tabular}

* Theoretical values of the oligosaccharide with the given composition.

$\dagger$ n.d.: not determined.

TABLE 2. Effects of exo-glycosidases on the asialo-derivative of the urinary sialooligosaccharide (moles per mole of the oligosaccharide)

\begin{tabular}{|c|c|c|c|}
\hline Enzyme applied & Galactose & Mannose & N-Acetylglucosamine \\
\hline$\beta$-Galactosidase & 1.0 & - & - \\
\hline$\beta$-N-Acetylhexosaminidase & - & - & tr. \\
\hline$\alpha$-Mannosidase & - & - & - \\
\hline $\begin{array}{l}\beta \text {-Galactosidase } \\
\quad \text { then } \beta \text {-N-acetylhexosaminidase } \\
\beta \text {-Galactosidase }\end{array}$ & 0.9 & & 1.0 \\
\hline $\begin{array}{l}\text { then } \alpha \text {-mannosidase } \\
\beta \text {-Galactosidase }\end{array}$ & 1.0 & & \\
\hline $\begin{array}{l}\text { then } \beta-\mathrm{N} \text {-acetylhexosaminidase } \\
\text { then } \alpha \text {-mannosidase }\end{array}$ & 1.2 & 1.0 & 1.4 \\
\hline
\end{tabular}

tr.; trace amount. 
TABLE 3. Methyl ethers of the alditols obtained in the methylation analysis

\begin{tabular}{|c|c|c|c|c|c|c|}
\hline \multirow{2}{*}{ Samale } & \multicolumn{6}{|c|}{ Methyl ether obtained } \\
\hline & $\begin{array}{l}\text { 2,3,4,6- } \mathrm{Me}_{4} \\
\text { Gal.oH }\end{array}$ & $\begin{array}{l}\text { 2,3,4-Me } \mathrm{A}_{3}- \\
\text { Gal-OH }\end{array}$ & $\begin{array}{l}2,3,4,6-\mathrm{Me}_{4^{-}} \\
\text {Man-OH }\end{array}$ & $\begin{array}{l}2,4,6-\mathrm{Me}_{3} \\
\text { Man-OH }\end{array}$ & $\begin{array}{l}\text { 3,4,6- } \mathrm{Me}_{3} \\
\text { Man-OH }\end{array}$ & $\begin{array}{l}\text { 3,6-Me- } \mathrm{Me}_{2}-\mathrm{N}- \\
\text { Me-GlcN-OH }\end{array}$ \\
\hline $\begin{array}{l}\text { Intact } \\
\text { sialooligosaccharide }\end{array}$ & - & 0.8 & - & 1.1 & 1.0 & + \\
\hline $\begin{array}{l}\text { Asialo-derivative of the } \\
\text { sialooligosaccharide }\end{array}$ & 1.0 & & & 0.9 & 1.0 & + \\
\hline $\begin{array}{l}\text { Dimannosyl-N- } \\
\text { acetylglucosamine }\end{array}$ & - & - & 0.9 & 1.0 & - & + \\
\hline
\end{tabular}

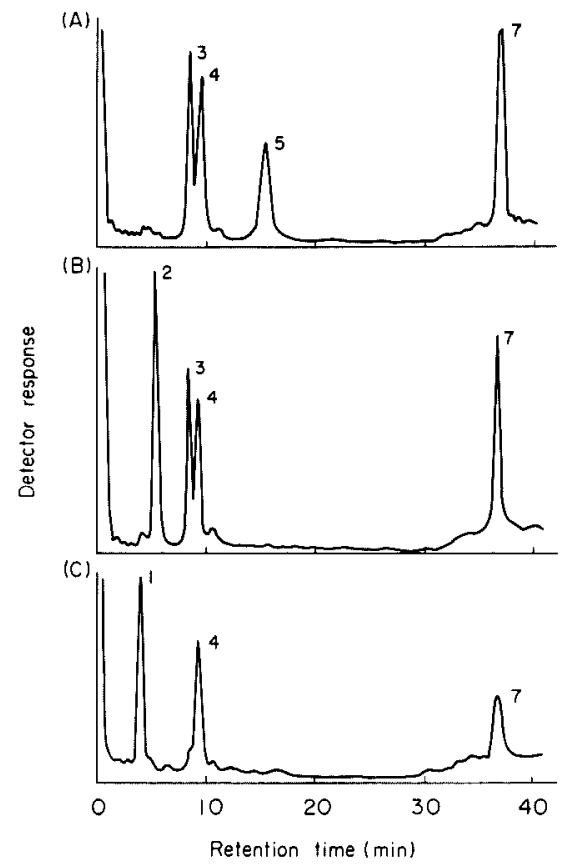

Fig. 3. Gas-liquid chromatograms of partially methylated alditol acetates obtained in the permethylation analysis of urinary sialooligosaccharide and its derivatives.

(A), intact sialooligosaccharide; (B), asialoderivative of the sialooligosaccharide; (C), Dimannosyl-N-acetylglucosamine obtained by sequential digestion of asialooligosaccharide with $\beta$-galactosidase and $\beta$-N-acetylhexosaminidase.

Peak 1, 2,3,4,6-tetra-0-methyl-D-mannose; peak 2, 2,3,4,6-tetra-O-methyl-D-galactose; peak 3, 3,4,6-tri-O-methyl-D-mannose; peak 4, 2,4,6-tri-O-methyl-D-mannose; peak 5, 2,3,4-tri-O-methyl-D-galactose; peak $6,2,4$ di-O-methyl-D-mannose; peak 7, 3,6-di-0methyl-N-methyl-D-glucosamine.

sialooligosaccharide possesses the following sequence and configuration of sugar constitu ents: Gal $\beta 1-4 \mathrm{GlcNAc} \beta 1-20$ 3Man- $\alpha 1-3$ or $2 M a n \beta 1-4 \mathrm{GlcNAc}$.

The gas chromatogram of the intact oligosaccharide was essentially identical with that of the asialo-derivative except that a peak corresponding to 2,3,4-tri-Omethyl-D-galactose was produced instead of a peak corresponding to 2,3,4,6-tetra-Omethyl-D-galactose. This observation suggests that the sialyl residue should be linked to the $\mathrm{C}-6$ position of terminal galactose residue in the asialo-derivative of the sialooligosaccharide. Dimannosyl-N-acetylglucosamine, which had been obtained by the sequential digestion of the asialo-derivative of the sialooligosaccharide with $\beta$-galactosidase and $\beta$ - $\mathrm{N}$-acetylhexosaminidase, produced an equimolar amount of 2,3,4,6-tetra-O-methyl-D-mannose and 2,4,6-tri-0-methyl-D-mannose. This result indicates that the trisaccharide has the following structure: Manal-3Man $\beta 1-4 G l c N A c$. 
The data obtained by the permethylation analysis, together with other results, indicate that the urinary sialooligosaccharide possesses the following structure:

$$
\text { NANA } \alpha 2-6 \mathrm{Gal} \beta 1-4 \mathrm{GlcNAc} \beta 1-2 \mathrm{Man} \alpha 1-3 \mathrm{Man} \beta 1-4 \mathrm{GlcNAc}
$$

The Smith degradation of the sialooligosaccharide revealed that the consumption of periodate reached a plateau after oxidation for $24 \mathrm{hr}$, which corresponded to 5 moles of periodate per mole of the sialooligosaccharide. The sugar composition of the Smith degradation product is listed in Table 4 . The results are fairly compatible with the results obtained by the enzymatic study, and by the methylation analysis.

Table 4. Analysis of the Smith degradation product of the urinary sialooligosaccharide

\begin{tabular}{ll} 
Periodate consumption (moles/mole) & $\mathbf{5 . 2}(5.0)$ \\
Galactose & n.d.* \\
Mannose & $0.9(1.0)$ \\
Glucosamine & $1.0(1.0)$ \\
NANA & n.d. \\
Glucosaminitol & $+(\mathbf{1 . 0})$ \\
Glycerol & $\mathbf{2 . 1 ( 2 . 0 )}$ \\
\hline
\end{tabular}

Values are expressed as molar ratio to glucosamine.

Values in the parentheses are theoretical values.

* not detectable.

\section{Discussion}

It is clear from the study described here that the sialooligosaccharide isolated from the urine of a patient with "mucolipidosis" has the chemical structure closely resembling the carbohydrate side chains of glycoproteins with aspartylglucosylamine type linkage region. So it is highly possible that the oligosaccharide described here would be derived from incomplete catabolism of such glycoproteins due to the disturbance of the enzyme activity responsible for the degradation of glycoproteins.

Some investigators reported that an alteration in the metabolism of sialic acidcontaining materials was involved in mucolipidosis. Dawson et al. (1972) described the accumulation of sialic acid-containing glycolipids in mucolipidosis II, and Thomas et al. (1976) observed the high level of sialic acid content in cultured fibroblasts from a patient with mucolipidosis II. Berman et al. (1974) isolated sialic acid-containing materials from the urine of patients with mucolipidosis III and they also observed a high content of sialic acid in the extract of leukocytes from the patients with this disease. These reports strongly indicate that mucolipidosis could be regarded as a metabolic disorder of sialic acid-containing substances. This assumption would be in agreement with the suggestion presented by Vladutiu and Rattazzi (1975) that the higher negative charge of the isozymes of $\beta$-N-acetylhexosaminidase, which are excreted by cultured fibroblasts derived from patients with I-cell disease, would be due to the presence of additional sialic acid not present on the normal enzyme molecule. 
Observations obtained by the present study are fairly coincident with the above-mentioned previous works, and the chemical structure of the sialooligosaccharide identified in the present study strongly suggests that the mucolipidosis described here can be classified biochemically as a new type of lysosomal storage disease characterized by an abnormal metabolism of glycoproteins having aspartylglucosylamine type side chains.

\section{Acknowledgment}

We would like to thank Dr. T. Orii, Sapporo Medical College, Sapporo, for supplying the urine specimen. This work was supported in part by a research grant from the Ministry of Education, Science and Culture, Japan.

\section{References}

1) Berman, E.R., Kohn, G., Yatziv, S. \& Stein, H. (1974) Acid hydrolase deficiencies and abnormal glycoproteins in mucolipidosis III (Pseudo-Hurler polydystrophy). Clin. chim. Acta, 52, 115-124.

2) Björndal, H., Lindberg, B. \& Svensson, S. (1967) Gas-liquid chromatography of partially methylated alditols as their acetates. Acta chem. scand., 21, 1801-1804.

3) Dawson, G., Matalon, R. \& Dorfman, A. (1972) Glycosphigolipids in cultured human skin fibroblasts. II. Characterization and metabolism in fibroblasts from patients with inborn errors of glycosphigolipid and mucopolysaccharide metabolism. J. biol. Chem., 247, 5951-5958.

4) Fukuda, M. \& Egami, F. (1971) The structure of a glycopeptide purified from porcine thyroglobulin. Biochem. $J ., 123,415-420$.

5) Hickman, S. \& Neufeld, E.F. (1972) A hypothesis for I-cell disease: defective hydrolases that do not enter lysosomes. Biochem. biophys. Res. Commun., 49, 992-999.

6) Koseki, M., Wu, J.-Y., Tsurumi, K. \& Nagai, (1978) Sialogluciduria in lysosomal diseases. Tohoku J. exp. Med., 124, 351-360.

7) Kuhn, R. \& Gauhe, A. (1965) Bestimmung der Bindungsstelle von Sialinsäureresten in Oligosacchariden mit Hilfe von Periodat. Chem. Ber., 98, 395-413.

8) Neufeld, E.F., Lim, T.W. \& Shapiro, L.J. (1976) Inherited disorders of lysosomal metabolism. Ann. Rev. Biochem., 44, 357-376.

9) Orii, T., Minami, R., Sukegawa, K., Sato, S., Tsugawa, S., Horino, K., Miura, R. \& Nakao, T. (1972) A new type of mucolipidosis with $\beta$-galactosidase deficiency and glycopeptiduria. Tohoku J. exp. Med., 107, 303-315.

10) Sandford, P.A. \& Conrad, H.E. (1966) The structure of the Aerobacter aerogenes A3 (SI) polysaccharide. I. A reexamination using improved procedure for methylation analysis. Biochemistry, 5, 1508-1517.

11) Spranger, J.W. \& Wiedemann, H.-R. (1970) The genetic mucolipidoses. Diagnosis and differential diagnosis. Humangenetik, 9, 113-139.

12) Tamura, Z., Imanari, T. \& Arakawa, Y. (1968) Gas chromatographic analysis of sugars in glycoproteins. Ikagaku Symposium (Proc. of the Symposium on chem. Physiol. and Pathol.), 8, 72-75. (in Japanese with English summary)

13) Thomas, G.H., Tiller, G.E., Jr., Reynolds, L.W., Miller, C.S. \& Bace, J.W. (1976) Increased level of sialic acid associated with a sialidase deficiency in I-cell disease (mucolipidosis II) fibroblasts. Biochem. biophys. Res. Commun., 71, 188-195.

14) Uchida, Y., Tsukada, Y. \& Sugimori, T. (1974) Distribution of neuraminidase in Arthrobacter and its purification by affinity chromatography. J. Biochem., 82, 14251433.

15) Vladutiu, G.D. \& Rattazzi, M.C. (1975) Abnormal lysosomal hydrolases excreted by cultured fibroblasts in I-cell disease (mucolipidosis II). Biochem. biophys. Res. Commun., 67, 956-964. 